\title{
Thermochemical Conversion of Waste Papers to Fuel Gas in a Microwave Plasma Reactor
}

\author{
Parin Khongkrapan, Nakorn Tippayawong, and Tanongkiat Kiatsiriroat
}

\begin{abstract}
In this work, a microwave plasma reactor for conversion of waste papers to generate fuel gas was developed and presented. Experiments were carried out with different air flow rates, focusing on product gas yield and composition. From the results obtained, it was shown that, at a constant input power of $800 \mathrm{~W}$, average gas yield and maximum carbon conversion obtained were $2.10 \mathrm{~m}^{3} / \mathrm{kg}$ and $59 \%$, respectively. On a nitrogen free basis, total content of $\mathrm{CO}$ and $\mathrm{H}_{2}$ in the gas product was $31-43 \%$, which can be used as synthetic gas.
\end{abstract}

Index Terms-Biomass, gasification, microwave plasma, renewable energy, solid waste.

\section{INTRODUCTION}

Wastes are generated on a daily basis, ranging from simple garbage to complex industrial waste. Amount of waste generated is very alarming. Total solid waste production in Thailand was over 35 kilotons/day. The per capita generation of municipal solid waste in the country was approximately $0.5-1.0 \mathrm{~kg} /$ day, with average value of $0.65 \mathrm{~kg} /$ day [1]. For a big city, total waste generated can be $1,000 \mathrm{t} /$ day or higher. The need to manage these municipal and industrial solid wastes is well recognized. Generally, technological strategies for disposal of solid wastes can be classified as (i) land-filling, with possibility of biogas recovery, (ii) incineration with recovery of energy, (iii) sorting of the wastes to recover materials that are recyclable, fermentable, or combustible, (iv) advanced approaches that aim at energy valorization. In most countries, emphasis has been placed on utilization of solid waste for generation of energy and electricity as an attractive alternative to landfills [2]. Waste-to-energy conversion in modern facilities with adequate and careful environmental monitoring has been shown to be a safe and cost effective technology. This is usually conducted with thermal technology such as combustion, gasification or pyrolysis because they can reduce the waste volume, toxicity, and produce a stream for further utilization [3].

Recently, plasma treatment of waste has emerged to offer a strong potential in waste disposal due to its fast process and ability to eliminate harmful substances. Plasma is the fourth state of matter. When the bonds between the electrons and ions are broken, the gas becomes electrically conducting plasma. The energetic species (electrons, ions, atoms, and

\footnotetext{
Manuscript received October 19, 2012; revised January 21, 2013. This work was supported by the Thailand's Energy Policy and Planning Office, and the Commission on Higher Education under National Research University Program.

The authors are with the Department of Mechanical Engineering, Faculty of Engineering, Chiang Mai University, Chiang Mai 50200 Thailand (e-mail: parin.khongkrapan@gmail.com; tanong@dome.eng.cmu.ac.th).
}

free radicals) initiated in the plasma may enhance desired chemical reactions. Plasma assisted reaction is a technologically advanced and environmentally friendly method to dispose of waste, converting it to commercially usable by-products, as well as fuels. Most plasma applications to waste management have so far been associated with thermal plasma [4]-[6]. Traditionally, plasma process uses arc plasma torch as the heat source. It requires high electrical energy to keep high temperatures in the plasma discharge. High energy consumption and low selectivity of some chemical processes are the main drawbacks of arc plasma. Non-equilibrium or non-thermal plasma technologies can offer alternative solutions.

Microwave plasma is non-thermal, easy to control and requires low power [7]. Microwaves are electromagnetic waves that have frequency range between $0.3-300 \mathrm{GHz}$. Microwave generation technology has been well established and widely commercialized. The microwave plasma can be generated using magnetron in typical household microwave ovens. It is simple, compact, robust and economical [8]. Many applications for microwave plasma have been reported, such as sterilization of germs, and surface modification of materials. However, there is still rather limited number of works reporting on microwave plasma and energy generation [9].

In this work, a microwave plasma reactor was developed for gasification of biomass. Waste paper was used as a feedstock. Effect of carrier gas flow rate on production of fuel gas via partial oxidation was investigated.

\section{Methodology}

\section{A. Feedstock}

Waste paper was the major component of combustible fraction of solid waste. In this work, the feedstock used was dry, shredded paper. It was sorted to uniform size. Composition of the sample paper [10] was shown in Table I.

TABLE I: COMPOSITION OF PAPER SAMPLES USED

\begin{tabular}{cc}
\hline \hline Component & Quantity $(\% \mathrm{w} / \mathrm{w}$, dry basis $)$ \\
\hline Carbon & 45.0 \\
Hydrogen & 6.1 \\
Oxygen & 42.4 \\
Nitrogen & 0.3 \\
Sulfur & 0.3 \\
Ash & 6.0 \\
\hline \hline
\end{tabular}

\section{B. Microwave Plasma Reactor}

The microwave plasma system in this work was modified 
from a commercial microwave oven. It consists of the $800 \mathrm{~W}$, $2.45 \mathrm{GHz}$ microwave generator, a cylindrical tube reactor, and auxiliary electrical equipment. The microwave radiation generated from the magnetron passed and guided through the oven cavity, and entered the discharge quartz tube centrally located inside the oven cavity. The plasma generated inside the tube was stabilized by injecting a carrier gas, which entered the tube from the bottom as a turbulent flow.

\section{Experimental Setup and Procedure}

The experimental setup is shown schematically in Fig. 1, equipped with gas cylinders for air and argon, connected to gas flow regulators.

A gas collection module was used for fuel gas conditioning and tar capture. It consists of a series of filter, impinger bottles containing a solvent for tar absorption placed in cold baths, and a moisture trap. Each impinger bottle was filled with approximately $100 \mathrm{ml}$ of isopropanol. The gas flow rates were measured with flow meters. The cool, dry, clean gas was sampled using gas bags and analyzed on a Shimadzu model GC-8A gas chromatography fitted with a ShinCarbon ST Micropacked column and a thermal conductivity detector, for measuring volumetric concentration of $\mathrm{H}_{2}, \mathrm{O}_{2}, \mathrm{~N}_{2}, \mathrm{CH}_{4}$, $\mathrm{CO}, \mathrm{CO}_{2}$. Standard gas mixtures were used for quantitative calibration.

Test and operating conditions were summarized in Table II. Initially, the quartz tube was loaded with shredded paper mass of $5 \mathrm{~g}$, before mounted inside the oven. Carrier gas was fed from the bottom of the reactor, varying between $1-4 \mathrm{lpm}$. The microwave generator was then switched on to start the reaction, and run for $4 \mathrm{~min}$. Gas collection was continually carried out. Solid residues were collected and weighed after each run. Each test was repeated in triplicate. Average values were reported.

\section{Data Analysis}

The following parameters are calculated [11]; Specific gas yield:

$$
S G Y=V_{\text {gas }} / W_{B}
$$

Carbon conversion efficiency:

$$
n_{c}=\frac{V_{g a s} \times \sum x_{i} \times(12 / 22.4)}{W_{B} \times\left(1-C_{A}\right) \times C_{c}} \times 100 \%
$$

Lower heating value:

$$
L H V=\sum x_{i} L H V_{i}
$$

where $V_{\text {gas }}$ is total volume of product gas generated, $W_{B}$ is converted mass of solid material, $x_{i}$ is volume fraction of fuel component of product gas, $C_{A}$ is carbon content in residue, $C_{C}$ is carbon content in biomass, and $L H V_{i}$ is the corresponding heating values of the gas component.

\section{RESUlTS AND DisCUSSIONS}

\section{A. Reactor Operation}

The microwave plasma reactor was operated at atmospheric pressure. The microwave was powered by a 2.45 $\mathrm{GHz}$ generator, whose continuous output power was constant at $800 \mathrm{~W}$. The discharge takes place inside a quartz tube with internal/external diameters of $27 / 30 \mathrm{~mm}$ and length of 250 $\mathrm{mm}$, inserted vertically and perpendicularly to the oven cavity. The plasma can be observed in the quartz reactor tube.

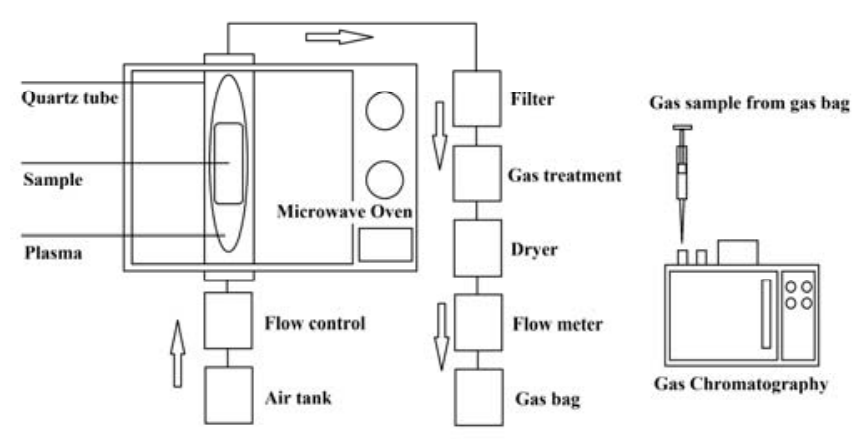

Fig. 1. Schematic of the microwave plasma reactor setup for gasification of waste papers.

TABLE II: OPERATING CONDITIONS OF MicRowAVE Plasma TESTS

\begin{tabular}{lc}
\hline \hline Parameter & Condition \\
\hline Input power & $800 \mathrm{~W}$ \\
Frequency & $2.45 \mathrm{GHz}$ \\
Pressure & $101 \mathrm{kPa}$ \\
Mass of paper & $5 \mathrm{~g}$ \\
Air flow rate & $1,2,3$ and $4 \mathrm{lpm}$ \\
Reaction time & $4 \mathrm{~min}$ \\
\hline \hline
\end{tabular}

TABLE III: PRODUCT GAS GENERATED

\begin{tabular}{|c|c|c|c|c|c|c|c|c|}
\hline Reference & Plasma source & power & Feedstock & Carrier gas & $\mathrm{H}_{2}(\%)$ & $\mathrm{CO}(\%)$ & $\mathrm{CO}_{2}(\%)$ & $\mathrm{CH}_{4}(\%)$ \\
\hline This work & Microwave & $800 \mathrm{~W}$ & Paper, $5 \mathrm{~g}$ & Air, 1-4 lpm & 7.7 & 8.5 & 8.7 & 1.1 \\
\hline$[12]$ & Microwave & $4500 \mathrm{~W}$ & Coal, $3-50 \mathrm{~kg} / \mathrm{h}$ & Air, $0-150 \mathrm{~kg} / \mathrm{h}$ & 2.4 & 8.1 & 9.6 & 1.2 \\
\hline$[14]$ & Microwave & $600 \mathrm{~W}$ & Polyethylene, $1 \mathrm{~g}$ & $0-20 \%$ steam/Ar, $3.5 \mathrm{lpm}$ & 14 & 26 & 12 & 6 \\
\hline$[15]$ & Microwave & $1000 \mathrm{~W}$ & Waste wood, $10 \mathrm{~g}$ & $\mathrm{Ar}, 1 \mathrm{lpm}$ & - & 56.9 & 33.8 & 0.5 \\
\hline$[16]$ & Gliding arc & $1140 \mathrm{~W}$ & Waste oil, $10 \mathrm{~g}$ & $10-30 \% \mathrm{O}_{2} / \mathrm{Ar}, 5-16 \mathrm{lpm}$ & - & 0.5 & 2.0 & - \\
\hline$[17]$ & $\mathrm{RF}, 13.6 \mathrm{MHz}$ & $2000 \mathrm{~W}$ & Sawdust, $0.3 \mathrm{~g} / \mathrm{min}$ & $\mathrm{N}_{2}, 0.5 \mathrm{lpm}$ & 8.5 & 11 & 4.0 & 1.5 \\
\hline
\end{tabular}

\begin{tabular}{cccc}
\hline \hline $\begin{array}{c}\text { Air flow rate } \\
(\mathrm{lpm})\end{array}$ & $\begin{array}{c}\text { Gas yields }\left(\mathrm{m}^{3} / \mathrm{kg}\right. \\
\text { paper })\end{array}$ & $\begin{array}{c}\text { Carbon conversion } \\
(\%)\end{array}$ & $\begin{array}{c}\mathrm{LHV} \\
\left(\mathrm{MJ} / \mathrm{m}^{3}\right)\end{array}$ \\
\hline 1 & 0.87 & 19.6 & 1.86 \\
2 & 1.71 & 38.8 & 1.93 \\
3 & 2.53 & 58.6 & 2.29 \\
4 & 3.29 & 51.1 & 1.56 \\
\hline \hline
\end{tabular}

TABLE IV: PERFORMANCE COMPARISON WITH LITERATURES 


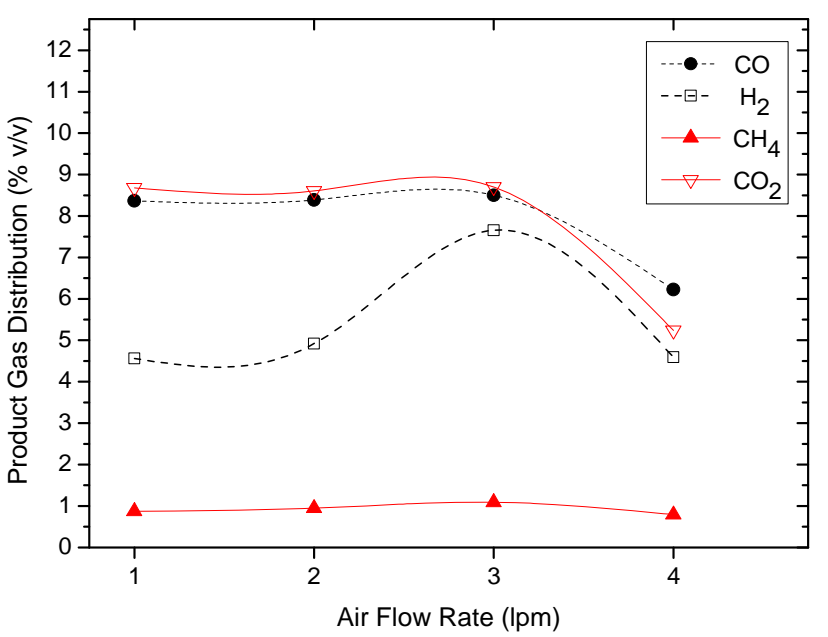

Fig. 2. Variation in concentrations of product gas generated with air flows.

The test run was performed for the microwave plasma system to confirm that the generated plasma can be achieved with our reactor. The plasma was characterized by high intensity light emission. It appeared to occupy most volume of the quartz tube inside the oven cavity.

\section{B. Fuel Gas Production}

Table III lists the gas yields, carbon conversion from those in solid material to those present in product gas, and corresponding heating values under different experimental conditions. For all test runs, there was about $1 \mathrm{~g}$ of solid residue left in the tube reactor. The specific gas yields obtained were found to increase with air supplied, as expected. Average gas yield was $2.10 \mathrm{~m}^{3} / \mathrm{kg}$ paper converted. However, carbon conversion and energy content of the product gas showed initial increase with increasing flow rate, reaching maximum at $3 \mathrm{lpm}$. Further increase in air supply led to reduction in conversion efficiency and LHV of the product gas. This was contributed to the fact that combustible gas components $\left(\mathrm{CO}, \mathrm{H}_{2}\right.$ and $\left.\mathrm{CH}_{4}\right)$ were found to peak at this flow rate, and drop at higher supply rate of carrier gas, as shown in Fig. 2. The observed decline in combustible fractions at higher flow rate may be due to the fact that the flow was too fast inside the reactor, hence, less likely for biomass material and the plasma to react with each other more completely.

\section{Comparison with Literature}

Product gas obtained from plasmochemical conversion of waste paper in this study was compared against those obtained from other types of biomass and carrier gas in microwave plasma reactors. Results are summarized in Table IV. With air plasma reaction, gas products obtained in this work were comparable to those in the literature.

\section{CONCLUSION AND FUtURE WORK}

In this paper, a laboratory scale, microwave plasma reactor has been described. This type of plasma was highly reactive, enabling conversion of solid materials into gas. Under oxidative environment, microwave plasma was able to generate combustible gas from waste paper. This is of practical interest for utilization of solid wastes for the purpose of fuel gas production. However, tests with regards to characterization of microwave plasma generated, as well as parametric investigation of operating conditions are still required. They are planned for the next stage of this research.

\section{ACKNOWLEDGMENT}

We wish to thank technical and secretarial assistance from Mr N. Kunnang, P. Thanompongchart, and T. Hanisch.

\section{REFERENCES}

[1] N. Tippayawong and J. Kinorn, "Refuse derived fuel as potential renewable energy source via pyrolysis," International Journal of Renewable Energy, vol. 2, pp. 45-51, 2007.

[2] S. Consonni, M. Giugliano, and M. Groso, "Alternative strategies for energy recovery from municipal solid waste part A: mass and energy balances," Waste Management, vol. 25, pp. 123-135, 2005.

[3] L. Bebar, P. Martinak, J. Hajek, P. Stehlik, Z. Hajny, and J. Oral, "Waste to energy in the field of thermal processing of waste," Applied Thermal Engineering, vol. 22, pp. 897-906, 2002.

[4] G. Bonizzoni, and E. Vassallo, "Plasma physics and technology; industrial applications," Vacuum, vol. 64, pp. 327-336, 2002.

[5] J. Heberlein, and A. B. Murphy, "Thermal plasma waste treatment," Journal of Physics D: Applied Physics, vol. 41, pp. 053001, 2008.

[6] E. Gomez, D. A. Rani, C. R. Cheeseman, D. Deegan, M. Wise, and A. R. Boccaccini, "Thermal plasma technology for the treatment of wastes: a critical review," Journal of Hazardous Materials, vol. 161, pp. 614-626, 2009.

[7] C. Tendero, C. Tixier, P. Tristant, J. Desmaison, and P. Leprince, "Atmospheric pressure plasmas: a review," Spectrochimica Acta Part $B$, vol. 61, pp. $2-30,2005$.

[8] H. S. Uhm, Y. C. Hong, and D. H. Shin, "A microwave plasma torch and its applications," Plasma Sources Science and Technology, vol. 15, pp. 26-34, 2006.

[9] C. J. Lupa, S. R. Wylie, A. Shaw, A. Al-Shamma'a, A. J. Sweetman, and B. M. J. Herbert, "Gas evolution and syngas heating value from advanced thermal treatment of waste using microwave-induced plasma," Renewable Energy, vol. 50, pp. 1065-1072, 2013.

[10] D. Tillman, Combustion of Solid Fuels and Waste, San Diego, USA: Academic Press, 1991.

[11] P. Lv, J. Chang, T. Wang, Y. Fu, and Y. Chen, "Hydrogen-rich gas production from biomass catalytic gasification," Energy and Fuels, vol. 18, pp. 228-233, 2004.

[12] P. M. Kanilo, V. I. Kazantsev, N. I. Rasyuk, K Schunemann, and D. M. Vavriv, "Microwave plasma combustion of coal," Fuel, vol. 82, pp. 187-193, 2003.

[13] X. Zhao, M. Wang, H. Liu, L. Li, C. Ma, and Z. Song, "A microwave reactor for characterization of pyrolyzed biomass," Bioresource Technology, vol. 104, pp. 673-678, 2012.

[14] H. Sekiguchi, and T. Orimo, "Gasification of polyethylene using steam plasma generated by microwave discharge," Thin Solid Films, vol. 457, pp. 44-47, 2004.

[15] C. J. Lupa, S. R. Wylie, A. Shaw, A. Al-Shamma'a, A. J. Sweetman, and B. M. J. Herbert, "Experimental analysis of biomass pyrolysis using microwave-induced plasma," Fuel Processing Technology, vol. 97, pp. 79-84, 2012.

[16] E. Kowalska, T. Opalinska, J. Radomska, and B. Ulejczyk, "Non-thermal plasma for oxidation of gaseous products originating from thermal treatment of wastes," Vacuum, vol. 82, pp. 1069-1074, 2008 .

[17] L. Tang and H. Huang, "Plasma pyrolysis of biomass for production of syngas and carbon adsorbent," Energy and Fuels, vol. 19, pp. 1174-1178, 2005.

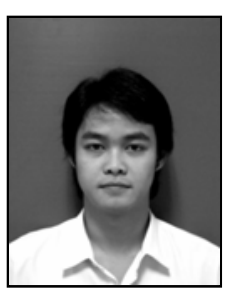

Parin Khongkrapan graduated with BEng and MEng degrees in mechanical engineering from Chiang Mai University, Chiang Mai, Thailand in 2005, and 2008 respectively. He was a lecturer at Rajamangkala University of Technology Lanna. He is currently working towards his $\mathrm{PhD}$ in sustainable energy at Chiang Mai University. 


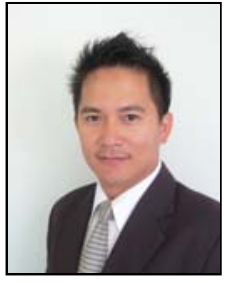

Nakorn Tippayawong received his BEng degree in mechanical engineering and $\mathrm{PhD}$ degree in internal combustion engines from Imperial College London, UK in 1996 and 2000, respectively. He is currently an associate professor at the Department of Mechanical Engineering, Faculty of Engineering, Chiang Mai University, Chiang Mai, Thailand. His research interests include biomass utilization, energy efficiency improvement, and emission control. So far, he has published more than 70 papers in peer reviewed international journals.

Dr Tippayawong is a senior member of APCBEES. He also serves as an editor, an associate editor and an editorial board member of several leading international journals.

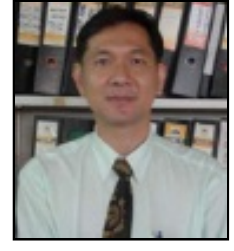

Tanongkiat Kiatsiriroat received his BEng and MEng degrees in mechanical engineering from Kasetsart University and King Mongkut University of Technology Thonburi, Thailand, and $\mathrm{PhD}$ degree in energy technology from Asian Institute of Technology, Bangkok, Thailand, respectively. He is currently a professor at the Department of Mechanical Engineering, Chiang Mai University. His research interests include thermal engineering, energy technology, and life cycle assessment. He has over 300 papers in peer reviewed national and international publications.

Prof Kiatsiriroat serves as an associate regional editor of Applied Thermal Engineering, as well as an editorial board member of various leading international journals. 